\title{
Towards a clearer understanding of 'vulnerability' in relation to chronic poverty
}

\author{
Prowse, Martin
}

Publication date:

2003

Document version

Early version, also known as pre-print

Citation for published version (APA):

Prowse, M. (2003). Towards a clearer understanding of 'vulnerability' in relation to chronic poverty. (Chronic Poverty Research Centre Working Paper No 24 ed.).

http://www.chronicpoverty.org/uploads/publication_files/WP24_Prowse.pdf 
Towards a clearer understanding of 'vulnerability' in relation to chronic poverty

\section{Martin Prowse \\ School of Economic Studies/ IDPM \\ Graduate School of Social Science and Law \\ University of Manchester}

E-mail: prowsemartin@ @otmail.com, martinprowse@ malawi.net

CPRC Working Paper No 24

April 2003

Chronic Poverty Research Centre

ISBN Number: 1-904049-23-0

I would like to thank David Hulme, Karen Moore, Colin Murray and Barbara Evers for commenting on previous versions of this paper. 


\section{Contents}

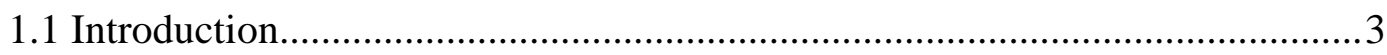

1.2 Hazards and vulnerability - a macro-level understanding ...............................

Section 2: A comparison of the ways in which vulnerability is conceptualised in the CPRC literature

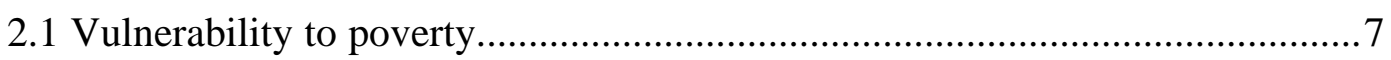

2.2 Vulnerability as a symptom of poverty.....................................................

2.3 Vulnerability as part of the multi-dimensional nature of poverty.................... 9

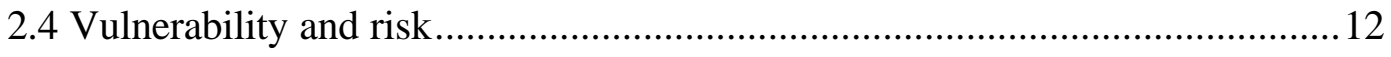

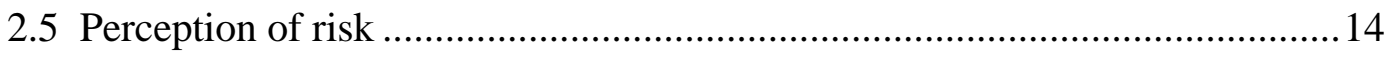

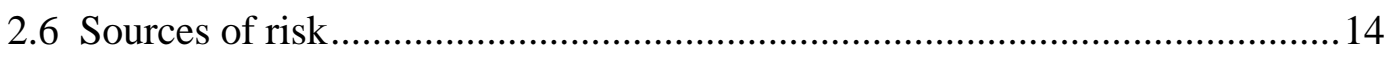

Section 3: A comparison of different approaches to disaggregating vulnerability

3.2 Vulnerability in 'Meanings' paper .........................................................2 21

3.3 Chambers and Ellis - internal and external .............................................22

3.4 Moser - sensitivity and resilience ......................................................... 23

3.5 Watts and Bohle - exposure, capacity and potentiality................................24

3.6 Sinha and Lipton - exposure, vulnerability and aversion ............................26

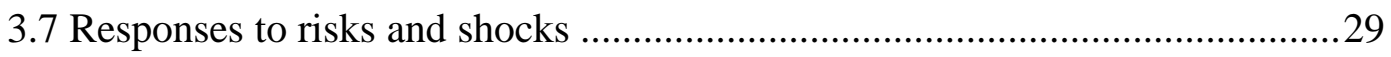

3.8 Vulnerability and response strategies in relation to chronic poverty................31

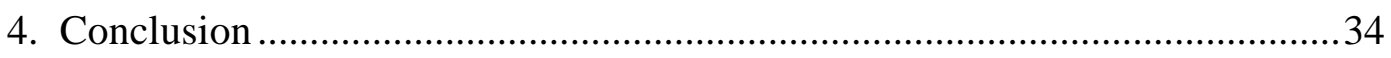




\section{Towards a clearer understanding of 'vulnerability' in relation to chronic poverty}

\subsection{Introduction}

This paper aims to analyse how the term 'vulnerability' has been used in the Chronic Poverty Research Centre's (CPRC) initial set of working papers. The intention of this analysis is to show that 'vulnerability' can be utilised in a variety of ways, with different meanings, and different implications. This attempt at unravelling vulnerability within the CPRC literature shows that there could be merit in disaggregating 'vulnerability', and that this could be relevant to the study of chronic poverty.

Whilst vulnerability has often been closely associated with poverty, it has also been seen as being distinct. Historically, vulnerability has been seen as a dynamic concept which recognises and captures change, whilst poverty has been seen as being static (Moser 1998, p.3). However, the increasing realisation that poverty itself is dynamic, "that some of the poor are not poor all of the time" (Yaqub 2000, p.1), means that the historical distinction between poverty and vulnerability has become less valid. Despite this, there is a continuing need for clear differentiation between poverty and vulnerability and this is obvious when one considers that "not all members of a particular vulnerable group are invariably poor" (Lok-Dessallien 1998, p.5), or that "all persons at the same level of income do not suffer equally in disaster situations nor do they encounter the same handicaps during the period of recovery" (Wisner 1993, p.127). In this respect, the study of poverty dynamics could benefit from engaging with, and incorporating, models or detailed conceptions of vulnerability.

When differentiating between poverty and vulnerability, it is important to highlight different uses of the two terms. Whilst poverty and vulnerability are both conditions, as seen in the stative sense of 'being poor' or 'being vulnerable', they must both also been seen as being processes. As highlighted above, both poverty and vulnerability are dynamic and are conditions which are constantly being altered, reinforced, or diminished. Additionally, poverty and vulnerability must also be seen as contested concepts as shown by the constant renegotiation of meaning attached to these terms and the subsequent influence this has on policy. 
It appears that there is a resurgence of interest in the concept of vulnerability with Devereux stating that "risk and vulnerability have been rediscovered as key features of rural livelihoods and poverty, and are currently a focus of policy attention" (Devereux 2001, p.507). Moreover, the recent recognition that better management of 'damaging fluctuations' and risks by those in or near poverty is, along with growth and redistribution, one of only three "proximate causes of poverty reduction" ${ }^{1}$ (Sinha and Lipton 1999, p.4) has meant that "vulnerability reduction is increasingly being seen as a central aspect of rural development policy" (Farrington et al. 2002, p.13).

\subsection{Hazards and vulnerability - a macro-level understanding}

The study of vulnerability in the poverty and 'development' literature stems, in part, from the study of hazards and disasters, in particular of famine, and is related to similar conceptions of marginality, resilience, susceptibility and adaptability (Wisner 1993, Kirkby et al. 2001). ${ }^{2}$ The increased use of the term through the 1970s and 1980s can be related to the emergence of a new paradigm in the study of hazards and disasters at this time. This structuralist paradigm asserted that physical hazards are distinct from the disasters that they potentially cause, the required linkage being a vulnerable population (Wisner 1993). The older paradigm in the study of hazards, termed the behavioural paradigm, views the cause of a disaster as being 'extreme forces of nature', and the poor perception of hazards and risk. It believes in the ability of technology, prediction, bureaucratic organisation and modernisation to mitigate disasters (Bankoff 2001, Smith 1996, Blaikie et al. 1994). ${ }^{3}$ The competing structuralist paradigm gives secondary importance to a 'natural' hazard as a determinant of a disaster (Blaikie et al. 1994).

Whilst both behavioural and structuralist schools of thought contend that disasters occur when there is an interaction between a 'natural' hazard and a population, they disagree over the extent to which a disaster is defined by either the severity of the hazard or the vulnerability of the population. ${ }^{4}$ The structuralist school of thought asserts that there is a need to place greater emphasis upon the vulnerability of a population as a determinant of a disaster, as this essentially decides whether a hazard remains a hazard, or whether through contact with a vulnerable population this hazard turns into a disaster. This is illustrated in Figure 1.

Evidence of the primacy of vulnerability as a determinant of a disaster is shown when one considers that between 1970 and 1985 over 97 percent of all the world's major naturat hazard triggered disasters and 99 percent of all disaster-related deaths occurred in the 'developing' world (Abbott 1991), and that in the 1990s at least 96 percent of the annual 
victims of natural hazards lived outside of Europe, Canada and the US (Walker and Walter cited in Bankoff 2001).

\section{Figure 1}

1.

Disasters occur when there is an interaction between a hazard and a vulnerable population.

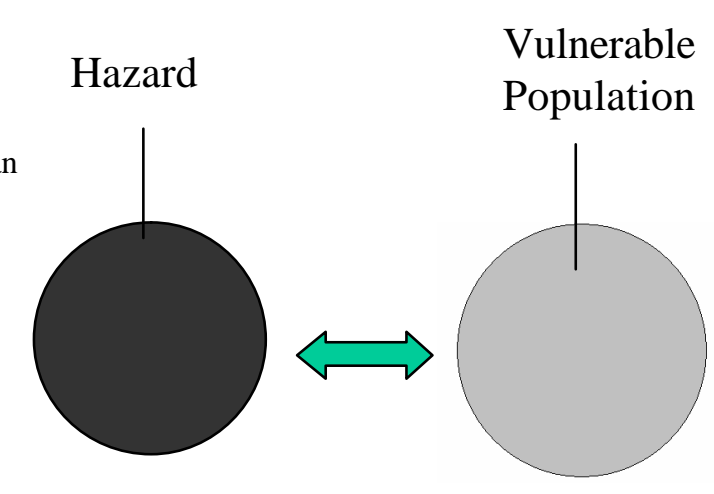

$\underline{2 .}$
Hazard
Vulnerable
Population

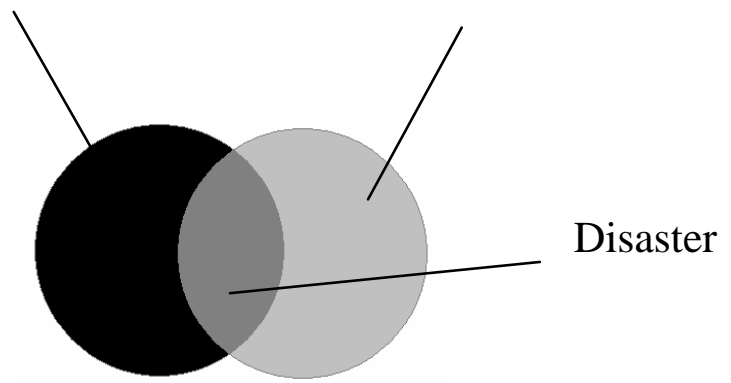

$\underline{3 .}$

There is a need to place greater emphasis upon vulnerability as a determinant of a disaster as this essentially decides whether the hazard remains a hazard, or whether through contact with a vulnerable population this hazard turns into a disaster.

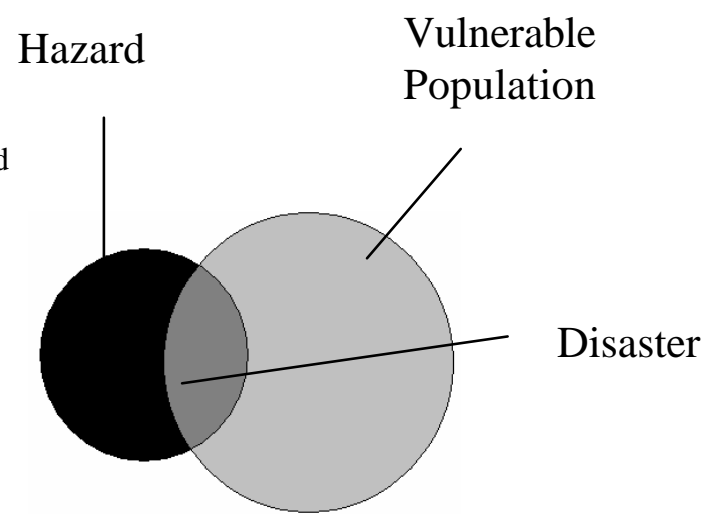


Such an understanding does, however, mask the diversity of experience of the 'poor', and does not assist in the formulation of assistance or intervention strategies. Moreover, the use of the word 'vulnerability' encourages a view of societies and people as 'passive' and non-responsive (Hewitt in Quarantelli 1998). In this sense the condition of 'vulnerability' appears to emphasise weakness, a lack of agency, and an inability to cope among 'affected' societies and people (Ibid., Bankoff 2001). Bankoff (2001) locates this 'condition' of vulnerability as a continuation of orientalist and ethnocentric depictions and denigration of the periphery which, on the one hand, renders these areas unsafe for 'western' peoples, and on the other hand, necessitates 'western' salvation through the application of western scientific rationality. From such a perspective Hewitt argues that "a generalised and abstract [structural] paradigm of vulnerability, is as unsatisfactory as the [behavioural] hazards paradigm" (Hewitt in Quarantelli 1998, p.82). Whilst it is clear for me that the structural paradigm constitutes a deepening in the understanding of hazards and disasters over the behavioural paradigm, there is an need to deconstruct and disaggregate vulnerability to not only achieve a more complex understanding of different constituent processes (Watts and Bohle 1993), but also to ensure that a structural understanding of hazards is analytically superior to, and clearly distinct from, a behavioural understanding. There is also a need to acknowledge Bankoff's (2001) critique as a useful antidote to the paternalism and ethnocentrism inherent in much poverty, hazard, and development literature. ${ }^{5}$ This is especially the case when one considers the continued dominant position of the behavioural paradigm within many multilateral and $\mathrm{UN}$ agencies (Bankoff 2001, Smith 1996).

The concept of vulnerability has been applied to a variety of levels and systems. Nations, cities, agricultural systems and organisations have been viewed through the vulnerability lens. The key point to note here is that within these systems or spaces it is individuals and households that are differentially vulnerable to hazards (Wisner 1993, p.127). It is at this level that an understanding of vulnerability needs to be reached because, as Dreze and Sen (1989) show, a lack of vulnerability at the national, regional or community level does not preclude extreme vulnerability at the individual level.

However, the ability to disaggregate poverty at the individual and household level and to gain a fuller understanding of vulnerability is limited because it is extremely difficult "to apply the concept of vulnerability to concrete situations" (Wisner 1993, p.127). This often leads to reducing vulnerability to a single causal factor. Such causal reductionism ignores the highly differentiated experience of individuals and households when placed under similar pressures and strains. The challenge therefore is to "create ways of analysing vulnerability implicit in daily life" (Wisner 1993, p.128). The analysis of individuals' and households' lives 
and livelihoods can uncover processes or points of weakness which can create, maintain and reproduce poverty.

The second section of this paper highlights the different ways in which CPRC working papers have used the term vulnerability. The third section critically compares different approaches to disaggregating vulnerability and highlights how these may be useful in relation to the study of chronic poverty.

\section{Section 2: A comparison of the ways in which vulnerability is conceptualised in the CPRC literature}

\subsection{Vulnerability to poverty}

A common use of 'vulnerability' in the CPRC Working Papers is in relation to being 'vulnerable to poverty'. In this sense vulnerability has been used to describe the potential for people to enter into poverty or chronic poverty. For example, Mehta and Shah (2001) describe how the "CPRC will examine the trends with respect to chronic poverty, explore the differentials in chronic poverty reduction and also try to understand the social, political and economic processes that increase/decrease vulnerability to chronic poverty" (p. 14). This emphasis on the potential to fall into chronic poverty stems from studies of poverty dynamics which show that a much higher percentage of a population experience poverty at some time than the percentage of the population experiencing poverty at a single point in time (see Yaqub 2000, Dercon 1999). For example, Okidi and Mugambe (2002) state that in the case of Uganda "the finding that the majority of the panel households had mixed status (moved in and out of poverty) suggests that vulnerability (the risk of slipping back into poverty) is reasonably high for a number of households" (p. 24).

This use of 'vulnerability' translates into a focus on the 'transient poor', and this reflects the fact that "research on vulnerability over the last two decades has fostered the understanding of transient poverty in rural areas" (Bird et al. 2002, p. 11). In the 5-tier categorisation system for poverty utilised by the CPRC (see Hulme et al. 2001, figure 3), the transient poor are both the 'churning poor' who fluctuate above and beneath the poverty line, and the 'occasionally poor' who occasionally dip into poverty due to an extreme decline in income. In this context 'vulnerability' in the sense of being 'vulnerable to poverty' is therefore focused on the 'transient poor', and does not focus on those already in poverty - the chronically poor. This raises a number of questions about vulnerability and chronic poverty: Are the chronically poor more vulnerable than the transient poor? What exactly are the 
chronically poor vulnerable to if they are already in poverty? Are the transient poor and the chronically poor vulnerable in different ways or to different phenomena?

A related yet distinct usage of 'vulnerability' within the CPRC literature is that deployed by Marcus and Wilkinson (2002) who focus on people who are "particularly vulnerable to the effects of poverty" (p.1). This change of emphasis, focusing on the outcomes of poverty, highlights the important difference between the means and ends of human welfare. Whilst the means of human welfare "refers to indicators of inputs intended to achieve an end result", such as income or the consumption of food or the use of health services, the ends of human welfare measures the outcomes themselves, such as life expectancy or nutrition or literacy (Lok-Dessallien 1998, p.7; Henninger 1998). This focus on the ends of human welfare, often described as human capabilities, is commonly associated with Sen's work on entitlements, capabilities and functionings (Sen 1981, 1984, 1999; Dreze and Sen 1989).

The change of emphasis onto the outcomes of poverty is of immediate and direct relevance to the study of chronic poverty. The emphasis on the ends of human welfare such as nutrition or literacy highlights key mechanisms through which the extended duration of poverty, which distinguishes the chronically poor, can be reproduced.

\subsection{Vulnerability as a symptom of poverty}

A further common use of the term vulnerability in the CPRC literature is in the sense of being 'vulnerable to shocks'. For example, Tudawe (2002) states that in the case of Sri Lanka "all the given information basically shows the degree of financial asset instability and high vulnerability to externalities, which contributes to the poor remaining poor for long periods of time" (p.30). In this sense, 'vulnerability to shocks' is seen as being a cause of chronic poverty. However, Okidi and Mugambe (2002, p.7) state that vulnerability to shocks is not just a cause of poverty but is also a symptom of poverty. This is highlighted by Baulch and Hoddinot (2000) who state that "households with greater endowments and greater returns will tend to be less vulnerable to shocks. After all, Sen's [1981] influential Poverty and Famines was so entitled to remind us that vulnerability to shocks is intimately linked to poverty" (p.19). Such an emphasis on vulnerability being an effect of poverty focuses attention on the mutually-reinforcing nature of poverty and vulnerability. The concept that vulnerability is both a cause and symptom of poverty reinforces the need for a more nuanced understanding of vulnerability than just being 'vulnerable to poverty'. 


\subsection{Vulnerability as part of the multi-dimensional nature of poverty}

'Vulnerability' in the CPRC literature is also described as being part of the multiple dimensions of poverty which are not usually captured by income- or consumption-based indicators of welfare. Hulme et al. (2001) highlight how this wider conception of poverty has been expanded to include "education, health, credit, participation in the political process, security and dignity" (p.6). The increasing acceptance of such a multidimensional conception of poverty is shown by a World Bank definition of poverty which includes "material deprivation, low levels of education and health, exposure to vulnerability and risk, and voicelessness and powerlessness" (cited in Hulme et al., p.7). In this definition "exposure to vulnerability and risk' is seen as being one of many constituent elements of poverty. What this definition indicates is that in addition to being a cause of poverty and a symptom of poverty, vulnerability can also be conceived as being part of poverty itself. An understanding of vulnerability as being a component of poverty is touched upon by Morduch (1994) and Sinha and Lipton (1999). For example, Sinha and Lipton (1999) highlight the issue that "vulnerability in bad times, or timidity at all times, in face of exposure to DF [damaging fluctuations] (including risk) is an important, and sometimes neglected, component of poverty" (p.12). Moreover, Morduch (1994) states that "while the effects of risk on expected poverty and income processes have been considered, no consideration has been given to the place of risk as a component of poverty “ (p.224). Morduch continues by arguing for an inclusion of a measure of vulnerability within the multiple dimensions of poverty:

"Vulnerability to income shocks may be intrinsically detrimental to the poor, and, just as deprivations in health and nutrition may be considered as part of an expanded poverty concept, one could also consider a measure of lack of access to consumptionsmoothing mechanisms" (Ibid.).

The extent which this proposal has been pursued is not clear, and as Morduch (1994) notes such a measure is fraught with difficulties.

\section{Quantifying vulnerability}

In explicitly recognising that "vulnerability is an important aspect of households' experience of poverty", Pritchett et al. (2000) attempt to quantify vulnerability by constructing a 'Vulnerability to Poverty Line' (VPL) as a level of expenditure below which a household has a greater than fifty percent probability of falling into poverty within a certain time period. In this sense Pritchett et al. define vulnerability as the probability that a household has a greater chance than not of experiencing an episode of poverty within a stated 
length of time. This VPL for a household is a function of the time period, the variability of expenditure, and the vulnerability threshold. Pritchett et al. show that the VPL increases with both the variability of household expenditure, as this would increase the chance of encountering one episode of poverty, and the length of the time period in question, as the probability of an event occurring increases with time, for a given threshold of vulnerability. Pitchett et al. find, using two panel data sets from Indonesia, that using the VPL to create a 'Headcount Vulnerability Rate' shows that thirty to fifty percent of the population are 'vulnerable to poverty' with a headcount poverty rate of only twenty percent. Such a finding does not surprise the authors as "these high levels of vulnerability confirm the voluminous literature based on qualitative assessments of the importance of vulnerability in the analysis of poverty" (p.16).

Pritchett et al. acknowledge the drawbacks in their quantitative approach but feel that "while the proposed quantitative measure does not begin to capture all of the complex, multifaceted, dimensions of the concept of vulnerability, this measure at least begins to put vulnerability on a par with static poverty measures in analytic and policy interest." (p.2). This may well be the case but one of the major drawbacks of this approach to quantifying vulnerability is that it reduces vulnerability to only being a cause of poverty, not a symptom or component of poverty. What the paper does highlight, however, along with the finding that vulnerability to poverty is very much a symptom of expenditure variability, is the importance of conceptualising vulnerability, in part at least, as being the differential probability to loss.

Pritchett et al. distinguish between vulnerability as being a risk and being defined in degrees (for example between 0 and 1) and the state of being vulnerable (either 0 or 1). This reinforces the above distinction between the dynamic process of vulnerability, and the condition of being vulnerable. Pritchett et al. suggest that whilst all households have some vulnerability, the condition or state of being 'vulnerable' is reached when a household has an even or greater probability of entering poverty than not (when the degrees of risk are 0.5 or greater). Such a cut-off point delineates the vulnerable from the non-vulnerable and assists in drawing meaningful comparisons of 'vulnerability to poverty' across different social groups. For example, Pritchett et al. find that female-headed households have greater per capita mean expenditures but suffer from greater fluctuations in expenditures than male-headed households, thus leading to a higher 'vulnerability to poverty' rate (p.21). Such comparisons across social groups must be one of the key reasons for an analysis of vulnerability as it will highlight both causal mechanisms which create vulnerability and potential recipients for targeted interventions. 


\section{Psychological effects of poverty and chronic poverty}

Hulme, Moore and Shepherd (2001) describe how multidimensional aspects of poverty have emerged, in part, from subjective poverty assessments. Such participatory methods have highlighted the centrality of powerlessness, isolation, insecurity, low selfesteem, vulnerability, and psychological well-being in the experience of poverty (Heslop and Gorman 2002). The value of such assessments is "not in counting but in understanding hidden dimensions of poverty and analysing causality and processes by which people fall into and out of poverty" (Robb quoted in Heslop and Gorman 2002).

One aspect of this multidimensional space of poverty which merits particular attention is that of the psychological effects of poverty and chronic poverty, in particular "the manner in which these relate to poor people's sense of vulnerability and their coping strategies" (Hulme et al., p.19). The best example of this in the emergent CPRC literature is the South African overview paper by Aliber (2001). Here vulnerability is related directly to the condition of resignation. Whilst acknowledging the quantitative aspects of vulnerability, Aliber (2001) states that "on a deeper level the experience of vulnerability is an aspect of poverty in and of itself, that is, a palpable disturbance to one's 'peace of mind'" (p.29). Such disturbance is, of course, also experienced by the non-poor at moments of personal or societal crisis, but Aliber's attention to the psychological effects of poverty highlights an important example of where chronic poverty could be qualitatively different from more transient forms of poverty. Aliber goes further than just highlighting the psychological dimension of poverty and suggests that "closely related to the experience of vulnerability is the state of being resigned to always remaining poor. Resignation is perhaps the most succinct subjective correlate to the notion of chronic poverty, i.e. that the poverty will endure" (Aliber 2001, p.29). Aliber (2001) suggests that the effect of resignation also manifests itself in discouragement and risk aversion which further exacerbate vulnerability and poverty (risk aversion is discussed in section 3.6). What is clear from this discussion of some of the multidimensional aspects of chronic poverty is that, just as the term vulnerability is important in consumption, expenditure and money-metric discussions of chronic poverty, discussions of the multi-dimensional nature of chronic poverty also engage strongly with the concept of vulnerability. 


\title{
2.4 Vulnerability and risk
}

Key to the discussions of vulnerability and risk in the CPRC literature is the suggestion by Hulme et al. (2001) that:

\begin{abstract}
"What poor people are concerned about is not so much that their level of income, consumption or capabilities are low, but that they are likely to experience highly stressful declines in these levels, to the point of premature death. This approach suggests that poverty can be seen as the probability (actual or perceived) that a household will suddenly (but perhaps also gradually) reach a position with which it is unable to cope, leading to catastrophe" (p.9).
\end{abstract}

This definition of poverty can also be seen as a particularly accurate proxy for a definition of vulnerability, especially due to its emphasis on the risk (whether real or imagined) of being unable to cope. However, in the CPRC literature risk and vulnerability are viewed in different ways. For example, in a discussion of the 'Risk of Market Failure' Bird et al. (2002) highlight that vulnerability to risk may be greater in remote rural areas. This 'vulnerability to risk' is similar to the conception of 'vulnerability to shocks' and views vulnerability as a cause of poverty. For example, in the same paper risk appears to be placed as a precursor to vulnerability. This almost comes across in a linear fashion with risk being the initial step in an assumed chain of events: "there are numerous sources of risk...which make households more likely to suffer shocks and experience an erosion of assets, deepening their vulnerability to future shocks and damaging their ability to escape poverty" (Bird et al. 2002, p.18). This linear depiction of risk and vulnerability (Risk - Exposure to Shocks - Erosion of Assets Increased Vulnerability to Shocks - Shift Into or Persistence of Poverty) contrasts with the earlier conceptions of vulnerability as being a cause, constituent part, and symptom of poverty, and in a sense reduces vulnerability to again being only a cause of poverty. This is not to argue that risk is not central to the processes which create and perpetuate chronic poverty, but that a dominant focus on risks, whether covariant or singular, could sideline equally important structural and idiosyncratic bases to chronic poverty. It is also central to recognise that the outcome of risks depends on how individuals, households, interest groups or communities respond to risk, as an increase in risk can, for some more than others, also increase opportunities.

Discussions of risk and vulnerability can also be found in the overview papers on Sri Lanka (Tudawe 2002) and India (Mehta and Shah 2001). Tudawe (2002) argues that a lack of financial capital limits the ability of poor people to "manage risk and vulnerability" (p.28). This idea of managing vulnerability is important, and indicates the agency of people in limiting uncertainty through having enough capacity to deal with any exposure to risk and 
vulnerability. This relates to the difference between the internal and external sides to vulnerability which is discussed in section 3.3. Mehta and Shah (2001) highlight the relationship between risk and vulnerability through the work of Kozel and Parker (2001). These latter authors categorise the 'poor' into three groups; the destitute poor, the structural poor, and the 'mobile' poor. Interestingly, Kozel and Parker (2001) assert that, while risk and vulnerability were important for all three categories, it is particularly important for the destitute and structural poor. This contrasts with the common 'vulnerability to poverty' use of the 'vulnerability' found in the CPRC literature, which focuses on the 'transient poor', and instead sees the vulnerability of 'chronically poor' as being particularly important.

As risk is central to differing concepts of vulnerability it seems appropriate to highlight some key distinctions in relation to risk which will be important in latter discussions about how it is best to disaggregate vulnerability for the study of chronic poverty.

\section{Partial and total risks}

Total risks are those which impact upon a wide spectrum, or the full portfolio, of assets/activities whilst partial risks only influence a particular determinant of well-being (Sinha and Lipton 1999, p.7).

\section{Generic and specific risks}

Risks can be divided into those which affect large number of people due to geographical location or particular activities (also termed covariate risks) and those risks which are specific to an individual or household (also termed idiosyncratic risks) (Devereux 2001, Sinha and Lipton 1999). This is the scale of risk and uncertainty and can be related to macro(international), meso- (sub-national), and micro-levels (individual) (Devereux 2001, p.509)

\section{Known and unknown risks}

Risks come in the form of those which are expected or predictable and hence are known to some extent, and those risks which are unexpected, unpredictable, and unknown. Sinha and Lipton (1999) propose the term 'Damaging Fluctuation' (DF) as a description for a known risk whilst an unknown risk is termed as a 'Risky Damaging Fluctuation'. In this respect a DF can be more or less 'risky' depending on the extent to which is known and can be predicted. ${ }^{6}$ The continuum from damaging fluctuations to risky DFs used by Sinha and Lipton (1999) seems useful, and is related to the further distinction between DFs and worsening trends. 
Devereux (2001) highlights the difference between cyclical risks (such as seasonality), stochastic risks (such as flood-prone locations), and unpredictable downturns (such as financial crises) (Devereux 2001, p.510). ${ }^{7}$

\subsection{Perception of risk}

Whilst a traditional understanding of the perception of risk would contrast the everyday 'inaccurate' and 'irrational' perceptions of people against the 'real' scientific probability of risk (Oliver-Smith 1996, p.319), Smith (1996) outlines three general modes of understanding risk in relation to hazards:

?? Determinate perception - An understanding that seeks to impose order upon the random nature of risks and hazards, often by reference to an order or cycle of events.

?? Dissonant perception - Essentially threat denial, this type of understanding questions occurrence of past risks and hazards or rationalises them as 'freak' events.

?? Probabilistic perception - Most closely connected to idea of an informationresponsive rational evaluator of risk, this type of interpretation acknowledges the random nature of risks and their potential consequences. Often is associated with placing the responsibility of the threat to a higher authority such as God or government.

(summarised from Smith 1996, p.71)

People therefore have a variety of modes of understanding risks and such perceptions will change considering the experience of the individual and the social and cultural setting in which these understandings are formed. In this sense it should be recognised that "risk perception and assessment are grounded in the cultural norms and values that govern and are embedded in the relationship that human communities have with their physical and social environment" (Oliver-Smith 1996). Moreover, there is a need to move away from just viewing the perception of risks as being constrained solely by imperfect information but to recognise the relationship between structure and agency which can determine an understanding of, and response to, risk (for example see Wisner 1993, Kothari 2002).

\subsection{Sources of risk}

Henninger (1998) outlines five sources of risk which influence vulnerability:

?? Environmental risk (droughts, floods, and pests).

?? Market risk (price fluctuations, wage variability, and unemployment).

?? Political risk (changes in subsidies or prices, income transfers, and civil strife).

?? Social risk (reduction in community support and entitlements).

?? Health risk (exposure to diseases that prevent work). 
As Henninger notes, these risks only form part of the equation as the consequence of risk depends on the response by individuals or households to the risk. This relates to the internal and external sides of vulnerability discussed in section 3.3. Sinha and Lipton (1998) offer a review of the empirical evidence of risks by distinguishing between six different types of risky DFs:

?? Disease or injury

?? Violence, including domestic, criminal, and war-related.

?? Natural disaster.

?? Harvest failure.

?? Terms-of-trade deterioration, especially affecting the price of food relative to labour

?? Reduced access to productive or income-earning work.

(Sinha and Lipton 1999, p.8)

Sinha and Lipton (1998) suggest that these categories offer a potential window from which to assess how structural adjustment has influenced the 'poor', and suggest, somewhat contentiously, that adjustment is only likely to affect the last two categories. In this respect they highlight how early adjustment in the form of stabilisation plus liberalisation will exacerbate both categories of risk, but that through 'economic logic' longer term adjustment will "stimulate faster growth, and lead poor and labour-abundant countries to specialise in labour-intensive activities, in both cases raising the mean income of the poor and thus lowering their vulnerability to any given DF" (p.9).

There are two key points to be made here. Firstly, the hypothesis that raising the mean income of the poor not only homogenises a highly diverse social category (for example will all of the chronically poor be able to partake in such labour-intensive activities) but presumes that an increase in the means of well-being (income) will equate unproblematically to vulnerability reduction. This may not be the case. A major reason for this is highlighted by Sinha and Lipton themselves (p.9) who acknowledge that increased specialisation in incomegenerating activities may actually increase vulnerability as future risks would be total risks as opposed to previously having been partial risks in a diversified portfolio of activities.

Secondly, and more importantly, it can be argued that adjustment has a substantial influence on other areas of risk. This includes a direct influence on the risk associated with a 'Natural Disaster'. Unfortunately Sinha and Lipton (1999) appear to confuse a natural hazard with the potential consequent 'disaster', the connection being an interaction with a 'vulnerable' population (as discussed in section 1.2). In this respect, adjustment, at any stage, will have an important influence on the scale and severity of a 'disaster' as this is partially defined by the ability of individuals and households response to the hazard. Therefore Sinha 
and Lipton locate themselves firmly within the behavioural paradigm of understanding disasters. This has particular significance in relation to their conception of 'vulnerability' which is discussed in section 3.6.

The extent to which adjustment is a source of risk for populations is matched by the extent to which governments are also seen as sources of risk. For example, Baulch and Hoddinot (2000) highlight the states role in modifying the "economic, legal and political settings within which the household is embedded" (p.19) and provide the examples of how macro-economic instability and the rule and law can be important sources of risk. Wisner (1993) illustrates how the state can also be seen as a risk itself through denying the existence of hazard, directing violence towards sub-groups within the population, or orientating intervention efforts towards or away from particular locations or populations. It is interesting to note that whilst Government itself is highlighted as a source as risk along with Government policy, the discussions of structural adjustment as a source of risk highlight only the policies and not the institutions which promulgate these policies.

\section{Opportunity and Insecurity}

As previously stated, risk is not necessarily negative as the outcome of risks depends on how individuals, households, interest groups or communities respond to risk, as an increase in risk can also differentially increase opportunities. As Giddens notes:

"Risk is not just a negative phenomenon - something to be avoided or minimized. It is at the same time the energizing principle of a society that has broken away from tradition and nature... Opportunity and innovation are the positive sides of risk. No one can escape risk, of course, but there is a basic difference between the passive experience of risk and the active exploration... Risk isn't exactly the same as danger"

(Giddens cited in Yaqub 2000, p.2)

Yaqub (2000) highlights how the relationship between insecurity and opportunity appears frequently in debates of various scales including globalisation, the collapse of socialism, and relief interventions, and notes how such discussions fail to engage fully with the distinction between permanent and transitory elements of inequality or welfare. For example, Yaqub (2000) suggests that "fiscal belt-tightening is inescapable for macro-economic stabilisation in some countries, but the case of its detractors ultimately lies in whether such belt-tightening is so savage as to impair the permanent component of welfare (i.e. stabilised chronic poverty)" (p.3). The trade-off between insecurity and opportunity and its effect on the transitory and permanent components of welfare and inequality reminds us not only that economic growth 
brings differential opportunities and costs across individuals, households, social groups, and countries, but also that national and global economies are prone to periodic moments of crisis which generate large amounts of insecurity. Therefore the need for appropriate social protection policies, whether providing a social assistance function (reducing the frequency or severity of poverty) or a social insurance function (ensuring consumption smoothing and prevention of catastrophe), is essential (Devereux 2001, p.514).

On a broader note, insecurity and risk are very much central to current discourses about globalisation. Beck (2002), in his discussions about a 'world risk society', highlights how as a defining feature of modernity "risk inherently contains the concept of control" (p.40). ${ }^{8}$ Beck suggests, however, how currently the world faces 'uncontrollable risk', not in the sense of an increase in the frequency or severity of risks, but in the de-bounding of "unnatural, human-made, manufactured uncertainties" in spatial, temporal and social dimensions (p.41). By this Beck suggests that hazards such as climate change do not recognise borders, that nuclear waste or genetically modified foods have unknown future consequences, and, in social sense, that it is impossible to isolate who is responsible and accountable for such risks or financial crises. Beck categorises such de-bounded risks into ecological risks, global financial risks, and, after September $11^{\text {th }}$, global terror risks. Such risks are seen as exogenous to 'peripheral' countries who have little capacity for control and much greater potentiality for catastrophe (p.42). Moreover, Beck asserts that the key issue within the "world risk society' is "how to feign control over the uncontrollable" (p.41). This digression into social theory does not relate directly to chronic poverty and vulnerability but shows how risk, uncertainty, and vulnerability are key contested concepts which appear to be at the core of many current debates and discourses within the social sciences, and therefore merit detailed attention and analysis. It also begs the question to whether current attempts at reducing poverty, such as the Millenium Development Goals, are themselves perhaps an endeavour to 'feign control over the uncontrollable' in the sense of only tackling the symptoms and not the causes of inequality. 


\subsection{Social exclusion, social capital and vulnerability}

\section{Social exclusion}

In the CPRC literature the concepts of social exclusion and social capital are both related to vulnerability. For example, Aliber (2001) highlights the importance of social exclusion in the case of retrenched farm-workers in South Africa who are displaced not just from long-term employment but also long-term residence. This relates to Hulme et al.'s (2000) assertion that the concept of social exclusion can be used to cover some of the multidimensional aspects of poverty such as insecurity and resignation. In this sense, and as LokDessallien (1998) notes, social exclusion and a multi-dimensional understanding of poverty are hard to distinguish. The term 'social exclusion' appears to encourage a view of the 'excluded' as being distinct and outside of the functioning 'included' segment of society, instead of understanding the 'excluded' as being the flip-side of the same processes which create 'successful' segments of society. In this respect, Murray (2001) suggests that "the idea of 'differential [or adverse] incorporation' into the state, the market and civil society is perhaps more appropriate than the now conventionally predominant idea of social exclusion" (p.5). Moreover, the emergence of the concept of social exclusion within welfare-state nations (Hulme et al. 2000), and the particular nature of the French society from where the concept originated (Francis 2002), indicate that the application of the term requires caution. ${ }^{9}$ However, this is not to say that the term is obsolete when considering vulnerability . This is shown by Kothari (2002) who successfully utilises a social exclusion framework in analysing migration and chronic poverty and in this respect shows how the concept "can capture the range of economic and non-economic processes which inhibit or allow the movement of people and enables an understanding of the implications of migration in sustaining or overcoming exclusionary processes" (p.11).

\section{Social capital}

Vulnerability in the CPRC literature has also been associated with the concept of social capital. For example, in the CPRC working paper on Sri-Lanka, Tudawe (2002), who defines the notoriously slippery concept as being a "form of mutual assistance" (Tudawe 2002, p.33), locates the 'asset' in "social relationships [which] facilitate access to information, finance, state services, equipment, food and goods that raise the capacity of households to survive and prosper" (Tudawe 2002, p.33). In this sense social capital can be seen as an 'asset' which exists not in people but in relationships (Francis 2002). Tudawe (2002) highlights how such 'forms of mutual assistance' for poor households are not adept at coping 
with covariate risks as "such ties are more common with other poor households: they provide a key means of coping with risk and vulnerability but, because they are poor-to-poor ties, they can often only provide a small amount of support for a limited time" (p.33). In addition to recognising the potential shortfalls of 'social capital' as a coping strategy, it is also important to question the analytical value of the concept. Francis (2000) argues that this is partly due to practical issues such as measurement, but also because the concept has become so diffuse to be meaningless, especially due to the asocial and ahistorical usage of the term. ${ }^{10}$ Moreover, Fine (2001) rejects the term as for him social capital collapses social theory into a package which allows the non-economic to be understood in terms of market imperfections and rational choice, thus facilitating the colonisation of the social sciences by economics. Whilst this may or may not be the case, there is a distinct need to wary of using such a catch-all concept in studying chronic poverty and vulnerability. In this respect, the division of the term in Hulme et al. (2000) into socio-cultural and socio-political capital allows for more precise analysis, especially in terms of the intergenerational transmission of poverty (see Moore 2002). The above criticisms of social capital are not meant to deny the importance of social networks and 'informal safety nets' (for example see Devereux 2001, Moser 1998), but rather to suggest that the term itself adds no analytical value to the study of such phenomena.

The extent to which the intergenerational transmission of poverty is related with the study of vulnerability has not been covered in this paper, although the potential analytical connections between both subject areas seems a particularly fruitful area for future analysis. However, whilst the division of social capital into socio-cultural and socio-political capital is to be welcomed, the relatively uncritical exposure given by Moore (2001, pp. 13-15) to particular 'culture of poverty' arguments under the rubric of the intergenerational transmission of socio-cultural capital does give some cause for concern.

\section{Adverse incorporation}

A different way of conceptualising social capital, and a useful antidote to the many accounts that extol its virtues, is the idea of adverse incorporation. Wood (2000) explains that adverse incorporation describes the condition of managing "vulnerability through investing in and maintaining forms of social capital which produce desirable short-term, immediate outcomes and practical needs while postponing and putting at permanent risk more desirable forms of social capital which offer the strategic prospect of supporting needs and maintaining rights in the longer term" (Wood 2000, p.19-20). Adverse incorporation is therefore interested 
in both the quality of particular social interactions, especially in terms of intra-household interactions, and is a condition which is found widely in many 'developing' country contexts (Ibid.). What this different understanding of social capital highlights, apart from the potential of social capital to be a creator or maintainer of chronic poverty, is a key element to understanding the relationship between vulnerability and chronic poverty; the trade-off between essential short-term objectives and potential longer-term possibilities and opportunities.

A broader understanding of adverse incorporation, as indicated above, is connected to the idea 'differential incorporation' into state, market and civil society as opposed to being 'excluded' from these spheres. This conception of 'adverse incorporation' can be seen to be similar to the manner, at the macro-level, in which 'value chain analysis' focuses not just on the ability of firms or countries to participate in increased global trade patterns, but also on mode in which firms or countries are inserted into markets (for example see Kaplinsky 2000, p.5-6).

\subsection{Determinants of vulnerability in the CPRC literature}

The CPRC has focussed strongly on specific social groups who "are particularly susceptible to chronic poverty, and that are likely to experience multiple and overlapping vulnerabilities" (Hulme et al. 2002, p.2). These particular concerns of the CPRC, such as gender, age, violence, conflict, geography, inter-generational transfer, class and caste (see for example Woodhouse 2002, Bird et al. 2002, Moore 2001, Heslop and Gorman 2002, Mehta and Shah 2001, Aliber 2001) can also be seen as potential determinants of vulnerability. ${ }^{11}$ However, it is important to remember that the simple identification of 'vulnerable' groups is not sufficient as "not all members of a particular vulnerable group are invariably poor" (LokDessallien 1998, p.5), and that social groups are fractured in multiple and complex ways. In this vein, Marcus and Wilkinson (2002) note that not only can "the term 'vulnerable group' be stigmatising" but that it "can be inaccurate, camouflaging the strengths of marginalised and disadvantaged people and their contributions to society, and presenting a falsely homogenous picture of diverse situations" (p.37).

In relation to highlighting 'vulnerable' groups, Devereux (2001) notes how one method of studying vulnerability is to analyse the risks faced by different segments of a population differentiated by livelihood strategies or by demographics (p.510). Whilst noting the above caveats, this may be the easiest way to start analysing vulnerability in relation to chronic poverty, and such a task would be made easier by a framework for understanding vulnerability. 


\section{Section 3: A comparison of different approaches to disaggregating vulnerability}

\subsection{Capturing vulnerability: Meanings and analytical frameworks}

We have seen how increased attention is currently being paid to the 'concept' of vulnerability, and that just as the multidimensional nature of poverty is a complex subject to unravel, so vulnerability is also a phenomenon which is extremely hard to capture. For instance, Webb and Harinarayan (1999) assert that "assessing vulnerability is like trying to measure something that is not there. It is an absence of security, basic needs, social protection, political power and coping options" (p.298). Moreover, considering that vulnerability is a dynamic evolving process, the analysis of vulnerability trends through time offer more for analysis and comprehension than do static snap-shot pictures (Ibid.). This translates, at the micro-level, to an emphasis on household trajectories which can highlight both idiosyncratic factors, as well as "structural matrices of vulnerability" (Murray 2001, p.4; Hulme et al. 2001, Table 1). This, of course, reflects the recent emphasis on poverty dynamics. However, there seems to be very little merit in talking about concepts such as chronic vulnerability. It may be more useful to try and break down what vulnerability is, and try to relate the duration of poverty of the chronically poor to the different constituent parts of vulnerability.

\subsection{Vulnerability in 'Meanings' paper}

Firstly, it is necessary to look closely at the attention paid to vulnerability in the 'Meanings' paper (Hulme et al. 2001). As noted above, the implicit definition of vulnerability in the 'Meanings' paper as 'the probability of an inability to cope', frames the discussion and this highlights the importance of engaging with the relationship between risk and vulnerability. The 'Meanings' paper highlights Ellis's (2000) usage of the distinction between an external side to vulnerability (threats to livelihood security, i.e. shocks and risks) and an internal side of "risk management and coping capability" (which is defined by access to a range of assets) (Hulme et al. 2001, p.9). It is this distinction, initially proposed by Chambers, which forms the basis for a disaggregation of vulnerability. Hulme et al. (2001) also highlight the distinction between ex ante risk management strategies and ex post coping strategies. This distinction draws attention to the fact that "vulnerability is generally measured as variation after the fact" (Hulme et al. 2001, p.9), whilst the need for vulnerability assessment is greater before a shock or risk that increases vulnerability and poverty. The distinction between ex ante and ex post strategies is also a key component to a disaggregation of vulnerability, and is discussed in section 3.7. 


\subsection{Chambers and Ellis - internal and external}

The starting point in disaggregating vulnerability is the internal/external distinction proposed by Chambers $(1983,1989)$ :

"Vulnerability thus has two sides: an external side of risks, shocks, and stress to which an individual is subject to; and an internal side which is defenceless, meaning a lack of means to cope without damaging loss" (Chambers 1989, p.1).

This can be depicted in a simple diagram:

Figure 2: Chambers' external and internal sides to vulnerability

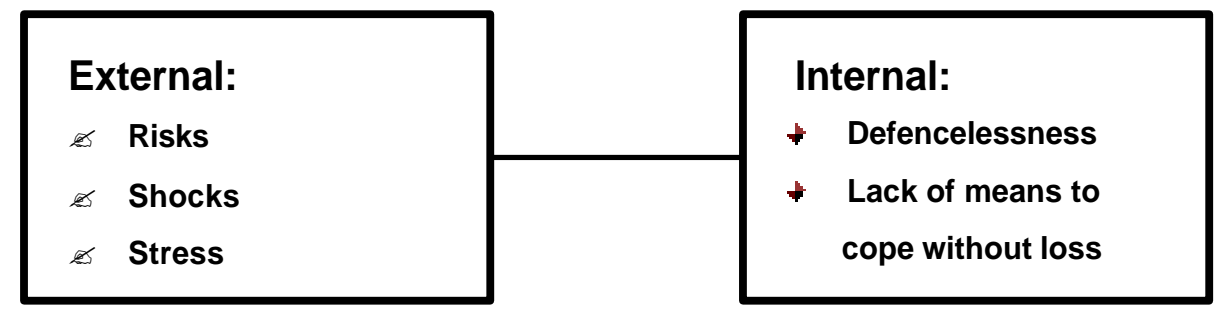

The two-step model of Chambers has been widely utilised (for example see Henninger 1998, Webb and Harinarayan 1999, Ellis 2000) and forms the basis of understanding vulnerability within the CPRC (see Hulme et al. 2001, p.9-10). It is very interesting to note this internal/external distinction at the micro-level (individual or household) replicates the key distinction in the 'disaster' literature at the macro-level about hazards and populations (see section 1.2). To recap, both behavioural and structuralist schools of thought regarding disasters contend that disasters occur when there is an interaction between a 'natural' hazard and a population, the structuralist school of thought asserts, however, that there is a need to place greater emphasis upon the vulnerability of a population as a determinant of a disaster (see figure 1). Evidence of the primacy of vulnerability as a determinant of a disaster is shown through the fact that nearly all deaths from disasters, triggered by natural hazards, are located in the 'developing' world, whilst hazards themselves are spread much more evenly (Abbott 1991, Smith 1996).

If this argument is transposed to the micro-scale internal/external distinction above, the argument that more emphasis needs to be placed upon the vulnerability of a population translates into an argument for more attention needing to be placed upon the internal element (the lack of access to a range of assets), as opposed to the external (shocks and risks). This 
observation is discussed shortly in a relation to Moser's conception of vulnerability. The internal/external model of vulnerability has been amended and adapted in various ways. For example, Devereux (2001) prefers to see the external element as "exposure to a threat", thus emphasising extent of interaction between the external and the internal, and the internal as "susceptibility or sensitivity to adverse consequences", thereby replacing the rather fatalistic notion on 'defencelessness' with a greater emphasis on the potential for loss (p.508). These subtle differences in the internal/external model are related to the conception of vulnerability in Moser's (1998) asset vulnerability framework.

\subsection{Moser - sensitivity and resilience}

Moser (1998) also utilises a two-step model of vulnerability but uses the concepts of sensitivity and resilience to significantly change the focus and emphasis of Chamber's internal/external distinction.

\section{Figure 2: Mosers' two dimensions to vulnerability}

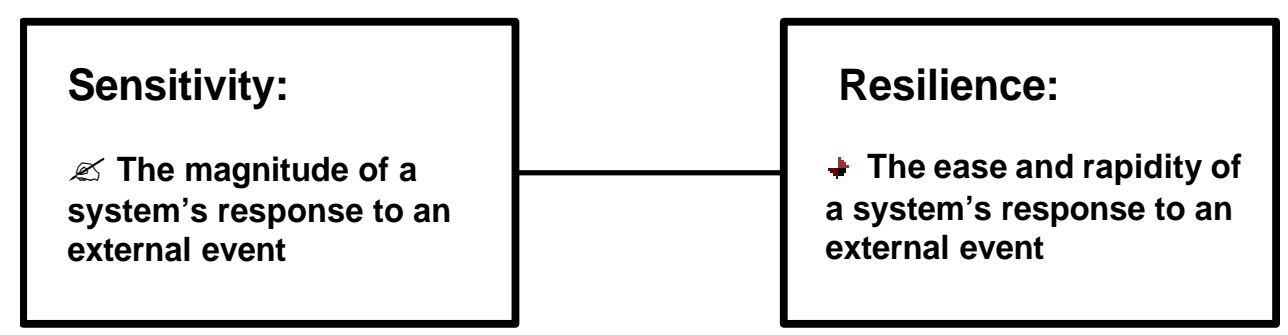

As Ellis notes (2000, p.62), the application of sensitivity and resilience to vulnerability stems from the fields of agro-ecology and natural resource management (for example Blaike and Brookfield 1987, Bayliss-Smith 1991). In this respect the ecological notions of an ecosystem's 'fragility' to external pressure and ability to 'bounce-back' from stress have been applied to individual or household livelihood systems (Ellis 2000, p.62-63).

The emphasis in the sensitivity/resilience model of vulnerability is twofold. The model emphasises the extent and severity of the interaction between the external 'hazard' and the internal 'capability' (sensitivity), and the tensile strength of the 'system' to recover from an external hazard (resilience). The model is therefore less 'fatalistic' than Chamber's internal/external and stresses the importance of the 'capability' of individual and household to respond to stress. This is reflected in the importance which Moser places on assets as the primary factor in determining vulnerability: 
"Analysing vulnerability involves identifying not only the threat but also the 'resilience' or responsiveness in exploiting opportunities, and in resisting or recovering from the negative effects of a changing environment. The means of resistance are the assets and entitlements that individuals, households, or communities can mobilise and manage in the face of hardship. Vulnerability is therefore closely linked to asset ownership. The more assets people have the less vulnerable they are, and the greater the erosion of people's assets, the greater their insecurity" (Moser 1998, p.3).

Moser is, however, very careful to indicate that people's capabilities in recovering from stress are influenced by "the social and psychological effects of deprivation and exclusion" such as hopelessness, especially during trends of long-term decline (Ibid.), thus reflecting the CPRC's concerns with the duration and multi-dimensionality of poverty. The importance that Moser places on assets and capabilities replicates, at the micro-level, the structuralist paradigm's assertion, at the macro-level, that more emphasis must be placed on internal element of vulnerability than the external risks or shocks. The reason why Moser appears to place such an emphasis on internal assets and capabilities can be illustrated through a further disaggregation of vulnerability.

\subsection{Watts and Bohle - exposure, capacity and potentiality}

The internal/external distinction of Chambers (1989) informed Watts and Bohle's (1993) definition of the 'space of vulnerability'. This sees exposure (risk of exposure to hazards) as the external side of vulnerability, whilst capacity (risk of inadequate capacity to mobilise resources to deal with hazards) and potentiality (the risk of severe consequences) form a more complex understanding of the internal side of vulnerability (figure 3 ):

\section{Figure 3: Watts and Bohle's 'space of vulnerability'}

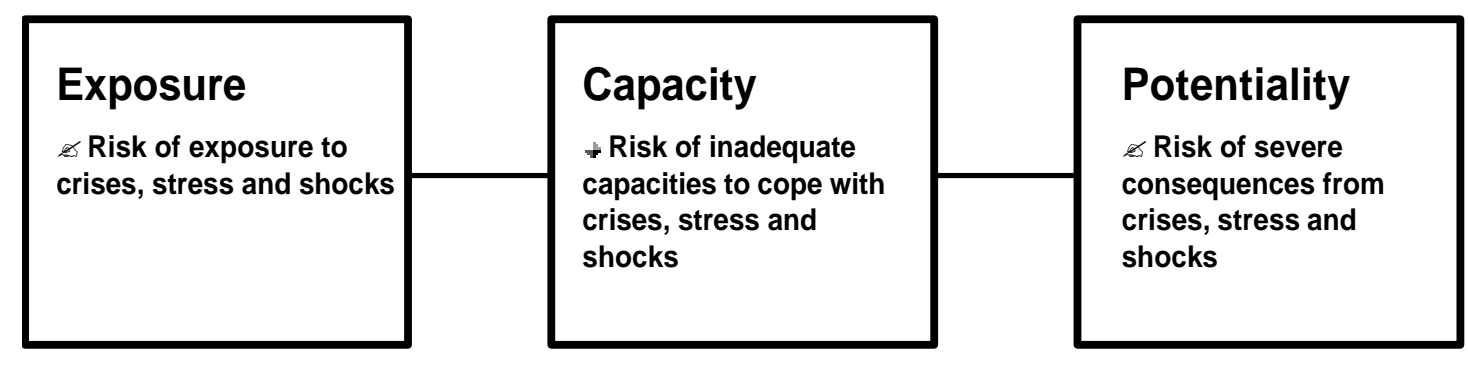

This three-step model adds a further dimension to vulnerability which is concerned with the downstream consequences of being exposed to a shock or stress, and not mobilising the resources to cope with the situation. Firstly, this model of vulnerability suggests why Moser's sensitivity/resiliency conception places such an emphasis on assets and capabilities. It could be argued that sensitivity in Moser's model brings together both the exposure and capacity 
aspects of the 'space of vulnerability' whilst the resilience aspect of vulnerability brings together both the capacity and potentiality aspects of the 'space of vulnerability'. This suggestion is illustrated in figure 4 .

Figure 4: Combining Moser's systemic approach with Watts and Bohle's three co-ordinates of vulnerability

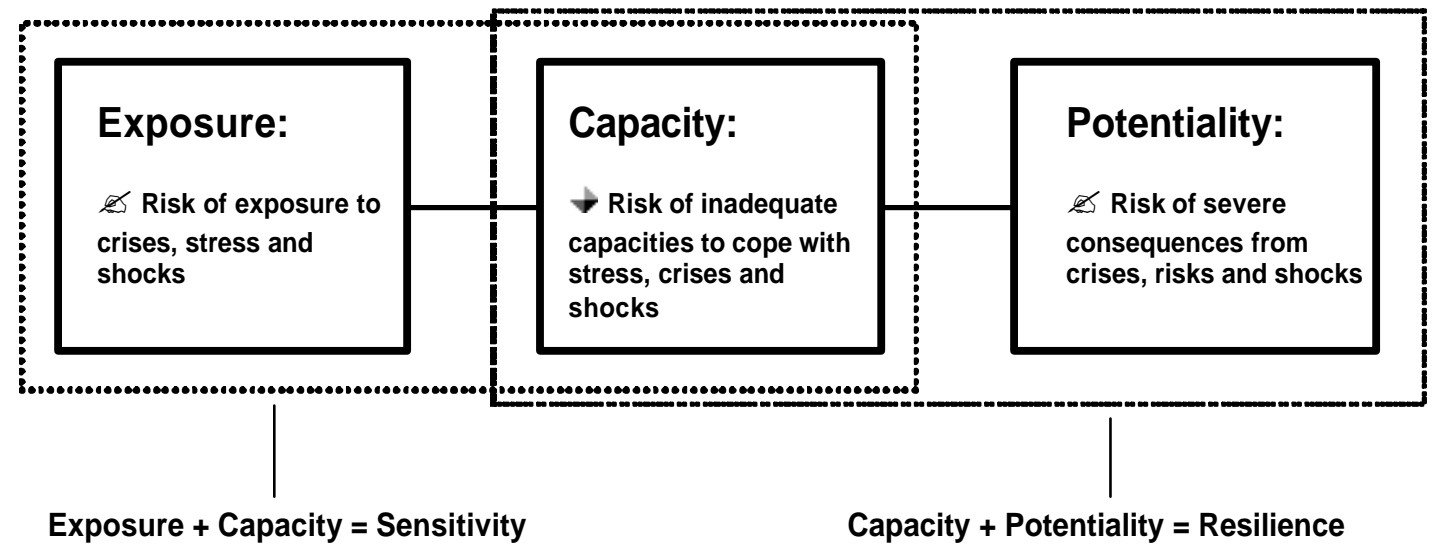

Figure 4 suggests that the reason why Moser places primary significance on assets and capabilities as a determinant of vulnerability is because both the sensitivity and resilience dimensions of her conception of vulnerability include capacity.

Secondly, it is through these co-ordinates of vulnerability that chronic poverty can be seen to be different from transient poverty. This is in terms of the potentiality of vulnerability. For the 'transient poor', the potentiality of suffering a shock, and not having the right capabilities, is an increase in poverty which may take the individual/household below a defined poverty line. The effect of this, however, is not permanent as 'transiently poor' households are more resilient and manage to escape poverty. This process is different for those who are chronically poor, or who become chronically poor. The potentiality of suffering a shock and not having the right resources to cope is in the case of chronically poor household not only an increase in poverty, but seems to be an extension to the duration of poverty, possibly leading to premature death. Therefore it is the extent of the potentiality of vulnerability, as influenced by exposure and capacity, which differentiates the transiently poor from the chronically poor. This analysis is very straightforward. However, a comparison with Sinha and Lipton's (1999) discussion of risk aversion, and the addition of 'coping strategies' into the equation, adds depth to this initial simplistic suggestion (section 3.7). The third point to note about the 'space of vulnerability' involves the balance which is struck between structure and agency in the analysis. This is through the manner in which Watts and Bohle (1993) highlight the three categories of entitle ments and capabilities, empowerment 
and enfranchisement, and political economy as contributing, often overlapping, dimensions to their understanding of vulnerability.

\subsection{Sinha and Lipton - exposure, vulnerability and aversion}

Sinha and Lipton (1999), in their in-depth and complex discussion of 'damaging fluctuations' (DFs) and risk, draw upon a schema which is remarkably similar to the 'space of vulnerability' outlined by Watts and Bohle (1993). Sinha and Lipton (1999) describe exposure to a DF (this is increased with size, frequency, earliness and bunching and correlates to what Watts and Bohle also describe as 'exposure'), the vulnerability to exposure (this increases with unpredictability, co-variance with other DFs and exposure relatively to the portfolio of assets and activities, this correlates roughly to 'capacity'), and aversion (this increases with exposure, vulnerability and experience, and correlates to 'potentiality') (figure 5).

Figure 5: Sinha and Lipton's model of exposure, vulnerability and aversion

\begin{tabular}{|c|c|c|}
\hline $\begin{array}{l}\text { Exposure to DF: } \\
\text { Increases with: } \\
\text { Size } \\
\text { Frequency } \\
\text { Earliness } \\
\text { Bunching }\end{array}$ & $\begin{array}{l}\text { Vulnerability to } \\
\text { DF: } \\
\text { To a given absolute } \\
\text { exposure this increases } \\
\text { with: } \\
\text { - Unpredictability } \\
\text { - Covariance } \\
\text { - Exposure relative to } \\
\text { portfolio } \\
\text { - Lack of resilience }\end{array}$ & $\begin{array}{l}\text { Aversion: } \\
\text { Increases with: } \\
\text { Exposure } \\
\text { Vulnerability } \\
\text { Past bad experience } \\
\text { of handling DFs }\end{array}$ \\
\hline
\end{tabular}

Whilst Sinha and Lipton's (1999) paper is very dense and in places suffers from a lack of clarity, some of the distinctions which are highlighted, and the depth to which they have approached the issue of risk and vulnerability, are extremely beneficial to this discussion (see section 2.4). In terms of the three dimensions associated with DFs illustrated above, Sinha and Lipton (1999) argue that the poor are generally, but not always, more exposed to common DFs, that the poor are more vulnerable to a DF exposure due to a lack of reserves, and that "DFs apart from inflicting misery in bad times, induce people to adopt cautious and nonentrepeneurial strategies in normal times, reducing their prospects of long-term advance" (Sinha and Lipton 1999, p.8). In relation to whether the poor are more risk-averse than the non-poor Sinha and Lipton assert that: 
"Though absolute risk aversion probably rises with falling expected income over most of the range, it may not do so at the bottom...[for example] the desperately poor may adopt a 'gambler's throw' strategy because disaster is almost inevitable" (Sinha and Lipton 1999, p.18).

For Sinha and Lipton, risk aversion therefore partially explains the duration of poverty for some of the chronically poor, as may the 'gambler's throw' strategy. The most common examples of risk aversion are that risky environments reduce investment, and that exposure to DFs means that livelihood strategy portfolios are often aimed more at consumptionsmoothing than high productivity (Baulch and Hoddinot 2000). Such consumptionsmoothing is often through the diversification of livelihood strategies with a low covariate risk between different activities (Ellis 2000). Whilst Moser argues that the most important determinant of vulnerability are assets and capabilities, Sinha and Lipton appear to place most emphasis on risk aversion. In this respect Sinha and Lipton appear to reduce the 'potentiality' of vulnerability in Watts and Bohle's formulation solely to risk aversion (compare figures 4 and 5).

This emphasis on risk aversion will be evaluated in relation to Sinha and Liptons discussion of the exposure to natural disasters and risks. ${ }^{12}$ Sinha and Lipton argue that there are 6 main types of DFs (see section 2.4) one of which are 'natural disasters'. They discuss each type of DF through the three co-ordinates of exposure, vulnerability and aversion. In terms of exposure to 'natural disasters', Sinha and Lipton assert that "exposure to risks from natural hazards arise essentially from location, in addition to behaviour" and feel that certain countries and cities are more 'prone' to natural disasters than others (p.27). The urban poor in developing countries are highlighted as being particularly exposed to risk through their location in risk-prone areas, poor infrastructure, and lack of land rights. More generally, Sinha and Lipton state that:

"So while prima facie residence in risk-prone regions/cities exposes all to risk, (i) the nonpoor are less likely to be living there, and (ii) their [the poor's] exposure arises from quality of housing, access only to marginal lands, limited access to markets, poor quality of livestock, etc. - factors that are direct correlates of poverty itself." (p.27).

In this respect Sinha and Lipton acknowledge that exposure to DFs is correlated to poverty (see section 2.2) and that this means that the poor are located in risk-prone areas. However, such an acknowledgement appears to cause considerable concern to Sinha and Lipton because "at first glance, this might appear to run contrary to the fact that the poor are more risk-averse than others" (p.27) as economic theory 'dictates' that "people specialise - and reside - in areas of their comparative advantage, which should mean risk-taking...for the rich, and risk- 
avoiding for the poor" (p.16). Sinha and Lipton therefore try to answer the following unfortunately-worded rhetorical question:

"How do we explain the apparent paradox that the poor nevertheless 'choose' to expose themelves to a wide range of natural disaster?" (p.27).

Curbed and constrained themselves Sinha and Lipton (1999) suggest that the poor:

"adopt a risky package of behaviour in face of disaster risks...in order to survive; to do this, they [the poor] reason, they are constrained to accept some disaster risks, so as to reduce what are perceived as more manageable and likelier income/consumption DFs" (p.27).

Therefore in this formulation the poor 'choose' to expose themselves to natural disasters so that they can manage more direct and obvious shocks. Following from this Sinha and Lipton contend that the consequences of 'choosing' high-risk exposure locations, are that "the poor are then more likely to be more averse to extra risk/DFs within those constraints" (p.27), thus presumably inhibiting entrepeunerial and risk-taking high-return productive activities.

There are three main points to mention in relation to this discussion of exposure. Firstly, the extent to which Sinha and Lipton uncritically use the term 'natural disaster' shows a lack of knowledge of the disaster, hazard and vulnerability literature as one would expect an appreciation that a disaster only occurs when a 'natural hazard' interacts with a population (see section 1.2). Secondly, the language chosen by Sinha and Lipton not only homogenises the 'poor' into an undifferentiated mass, but hugely overstate the ability of the poor to 'decide' their location and future. Thirdly, and connected to this last point, despite acknowledgeing that exposure to DFs is related to poverty, Sinha and Lipton locate the causal mechanism of this relationship solely within the actions (agency) of the poor themselves, i.e. the poor 'choose' a risky location so that they can manage more direct and obvious risks. This formulation could be acceptable if it was balanced with an acknowledgement of more structural and idiosyncratic factors which 'force' people into, or 'retain' people in, risky locations. As Kothari (2002) explains in relation to people who choose not to migrate out of marginal environments:

"Many people cannot move because of systemic, structural and individual reasons that reflect their experiences of exclusion or adverse incorporation. These include domestic and familial obligations and responsibilities, disability and illness, age, education and skills, and an absence or lack of access to networks and relationships. Thus movers and stayers alike are deeply embedded in specific economic and social-relational contexts" (p.14-15). 
However, Sinha and Lipton instead focus entirely on the evaluation of risk as the determinant of location. But in this respect Sinha and Lipton appear to tie themselves in knots for, on the one hand, risk-aversion is overcome by the rational evaluation of risk leading to locating in a marginal environment, but on the other hand the outcome and consequence of locating in a marginal environment is extreme risk-aversion to additional risks which is unproblematically seen as the main determinant of the perpetuation of poverty (can the 'poor' not overcome this risk-aversion as well?). This dubious reasoning highlights the inaccuracy of reducing the outcomes of vulnerability to solely risk aversion. In this respect, a wider conception of the consequences of vulnerability is required, which includes other, often inter-related, processes such as adverse incorporation and the psychological aspects of poverty, as well as riskaversion.

\subsection{Responses to risks and shocks}

One aspect of vulnerability which has so far been neglected is that of the response to risk, uncertainty and shocks. Hulme et al. (2001) highlight the distinction between ex ante risk management strategies and ex post coping strategies. Ellis (2000) defines ex ante risk management as consisting of "forward planning to spread risk across a diverse set of activities, in the context of subjective evaluations about the degree of risk attached to each source of risk" (Ellis 2000, p.62). ${ }^{13}$ Ex post coping strategies are defined as "the methods used by households to survive when confronted with unanticipated livelihood failure" in either a gradual or a sudden sense (Ibid.).

This distinction has been the starting point for additional angles of analysis. In terms of coping strategies Moser (1998), for example, highlights Devereux’s (1993) distinction between 'income-raising' coping strategies and 'consumption-modifying' coping strategies as being particularly useful for the urban context. Additionally, Moser (1998), Ellis (2000) and Devereux (2001) discuss the importance of 'strategy sequencing' as part of coping because "households facing food shortages are forced to trade off short-term consumption needs against longer term economic viability" (Devereux 2001, p.512). In this respect, Devereux (2001) highlights Corbett's (1988) typology of strategies with 'insurance mechanisms' preceding the 'disposal of productive assets' and subsequently 'destitution behaviour', with these strategies depending not only on its effectiveness but on its cost and reversibility. Devereux (2001) also highlights the importance of 'community support systems' or 'informal safety nets' as a particular type of coping strategy and defines these as "non-market transfers of goods and services between households" (p.513). Devereux (2001) suggests that in subSaharan Africa vertical redistributive practices, such as patron-client relations, appear to be 
becoming less common, and that horizontal practices are still widespread, but are very weak to covariant risks. Moser (1998) highlights the importance of such 'informal safety nets' in reducing vulnerability. In contrast to the above focus on ex post coping strategies, Sinha and Lipton (1999) draw distinctions within ex ante management strategies. In doing so Sinha and Lipton (1999) differentiate between DF-reducing and DF-mitigating strategies, which form a more complex side to ex ante risk management, and DF-coping strategies. This is summarised below:

?? DF-reduction: Involves removing or reducing the DF itself e.g. Irrigation

?? DF-mitigation: Involves reducing the negative impact of a particular type of DF through

(i) Protecting e.g. immunisation

(ii) Decoupling e.g. diversification

(iii) Forecasting e.g. delayed sowing

(iv) Consumption smoothing e.g. grain stores

(v) Credit e.g. insuring

?? DF-coping: Involves actions after a DF occurs e.g. Gathering of wild foods

(adapted from Sinha and Lipton 1999, p9-10)

It appears therefore that both ex ante risk management and ex post coping strategies have been differentiated in particular ways. This is crudely summarised is figure 6 .

\section{Figure 6}




\section{Responses to risks and shocks}

(Adapting)

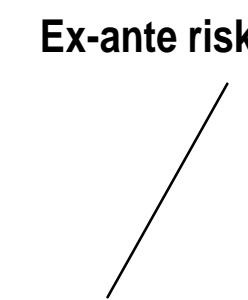

DF-reduction

Involves removing or reducing the DF itself e.g. Irrigation management

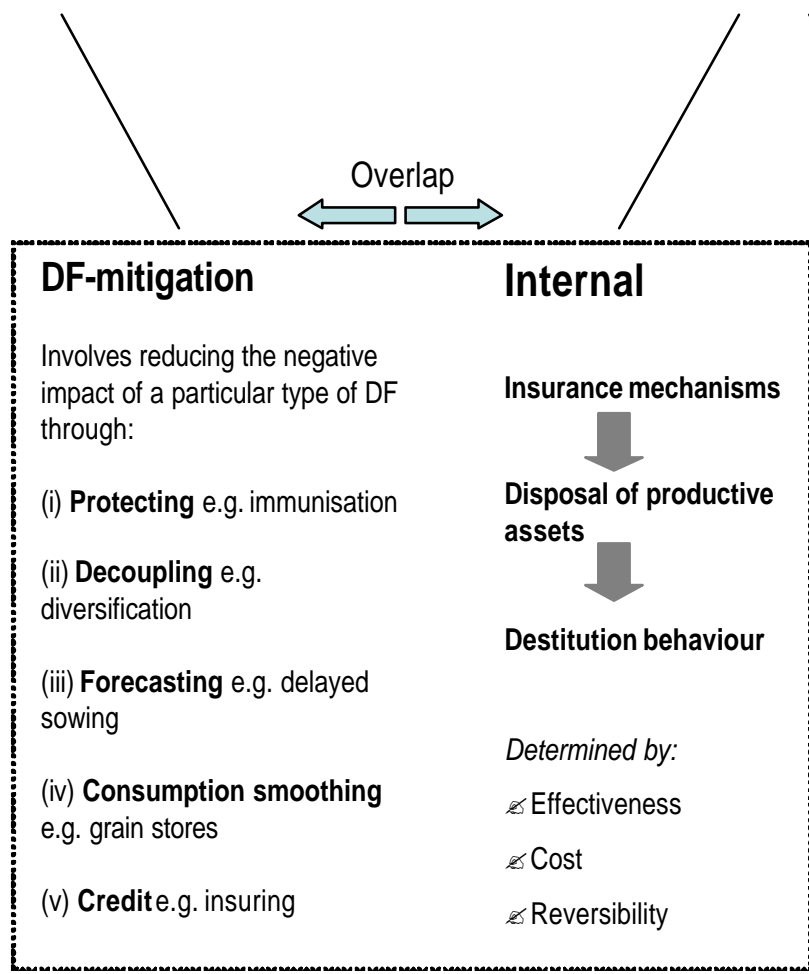

(Coping)

\section{Ex-post coping strategies}

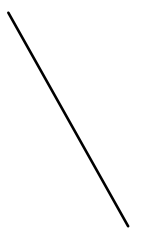

External

Informal Safety Nets

? Horizontal

? Vertical

(Adapted from Devereux 2001, Sinha and Lipton 1999, Moser 1998, Ellis 2000)

The above illustration has simply attempted to illustrate the various distinctions discussed above and does not attempt to resolve the tension between particular activities which can be seen as both risk management strategies and as coping strategies.

The most important aspect of the various responses to risks and shocks is the importance of time. In Sinha and Lipton's terms, DF-reduction is better than DF-mitigation which is better than coping. Therefore, ex-ante risk management is far preferable to ex-post coping strategies. This means, as stated previously, the challenge is to "create ways of analysing vulnerability implicit in daily life" (Wisner 1993, p.128) so that social protection measures, whether marketbased or public action, can be more effective by being aimed at risk management as opposed to coping strategies (Baulch and Hoddinot 2000, Devereux 2001).

3.8 Vulnerability and response strategies in relation to chronic poverty 
In trying to pull together the various discussions in this paper in a visual form, some important points merit further repetition. Firstly, that this paper agrees with Moser's (1998) focus on resistance and capability:

"The means of resistance are the assets and entitlements that individuals, households, or communities can mobilise and manage in the face of hardship. Vulnerability is therefore closely linked to asset ownership. The more assets people have the less vulnerable they are, and the greater the erosion of people's assets, the greater their insecurity" (Moser 1998, p.3).

Secondly, that reducing the consequences of vulnerability to solely 'risk aversion' negates further important aspects of the outcomes of vulnerability. This is especially important for the study of chronic poverty because it is the consequences of vulnerability which can be seen to differentiate the chronically poor (an extended duration of poverty or premature death) from the transiently poor (a increase in well-being above a certain threshold). And thirdly, that there is a need to try and explicitly link discussions and conceptual models of vulnerability and responses to risks and shocks.

These points are reflected in the following illustration which is a tentative attempt to suggest how vulnerability could be conceptualised in the study of chronic poverty. The illustration does not purport to be comprehensive but is a method of summarising many of the arguments in this paper, and will hopefully assist those wishing to analyse the issue of vulnerability in relation to chronic poverty. ${ }^{14}$

\section{Figure 7}




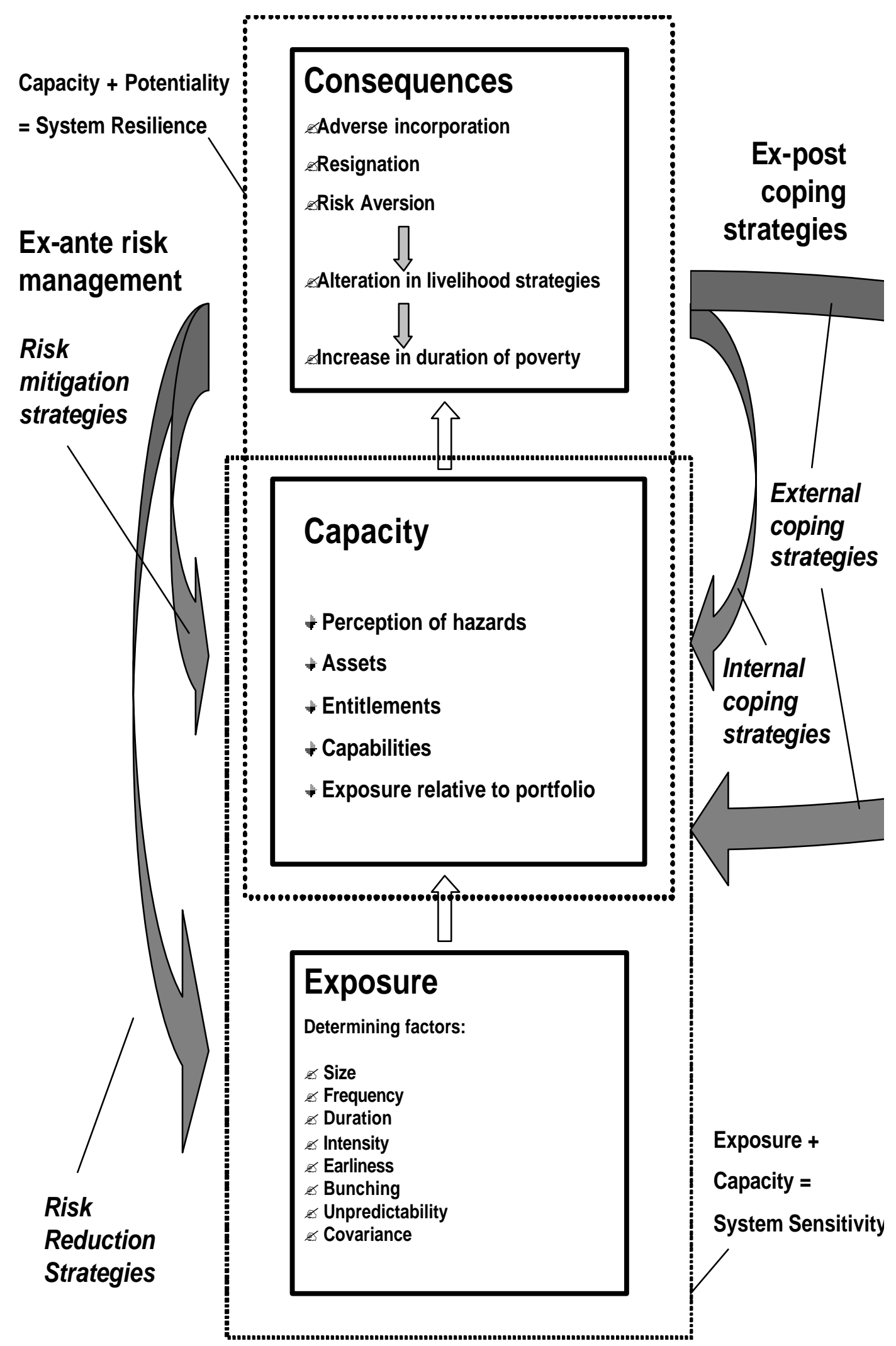

(Created from sources listed in this paper, especially Watts and Bohle 1993, Sinha and Lipton 1999, Moser 1998, Devereux 2001) 


\section{Conclusion}

"It will be important for CPRC researchers to engage with these issues of vulnerability, both in terms of differential vulnerabilities to shocks leading to spells of poverty, as well the manner in which vulnerability interacts with risk aversion to hinder escape from poverty, through, for example, adverse incorporation" (Hulme, Moore and Shepherd 2001, p.10).

This paper has outlined the ways in which the term 'vulnerability' has been used in the initial set of CPRC working papers. From this discussion, the paper has observed that a sole focus on 'vulnerability to poverty' means a primary concern with the transient poor as opposed to the chronically poor, and the paper has argued that vulnerability should be more widely recognised as being a cause, symptom and constituent part of poverty. Relating microscale discussions of vulnerability to a macro-level interpretation of hazards and disasters, the paper argues for the need to place an increased emphasis on the assets and entitlements for understanding individual 'catastrophe' as opposed to the strength or severity of shocks. Moreover, the paper has argued that reducing the consequences of vulnerability to solely 'risk aversion' negates further important aspects of the outcomes of vulnerability. This is especially important for the study of chronic poverty because it is the consequences of vulnerability which can be seen to differentiate the chronically poor from the transiently poor. Lastly, the paper has highlighted the need to try and link conceptual models of 'vulnerability' and 'responses to risks and shocks'. It is hoped that this discussion of differing conceptions of vulnerability has shown that there is a need for the CPRC to engage more systematically with the conception of vulnerability to assist with the analysis of the long duration of poverty which distinguishes the chronically poor. 


\section{Endnotes}

${ }^{1}$ When poverty is understood in a broad multidimensional sense.

${ }^{2}$ Vulnerability as a concept is also widely used in such fields as crime, health, mental health and human rights. Unfortunately this paper does not focus on the use of the term in these different literatures which would have added further dimensions to the concept. See Delor and Hubert (2000) for a summary of the use of vulnerability in the fields of crime and racial harassment, mental health, and people living with HIV/AIDS.

${ }^{3}$ Blaikie et al. differentiates between a strong physicalist/naturalist strand in this paradigm that places complete causation on 'the violent forces of nature', and a weaker strand of environmental determinism where "the limits of human rationality and consequent interpretation of nature lead to tragic misjudgements in our interactions with it" (Blaikie et al. 1994, p.11).

${ }^{4}$ The extent to which 'natural hazards' can still be seen as being 'natural' considering human's impact on the global environment (global warming, ozone depletion) is a contentious issue, and one which is not tackled in this paper (see Smith 1996).

${ }^{5}$ In Bankoff's (2001) critique of 'vulnerability' it is argued that the concept of 'vulnerability' is the current equivalent to the concepts of 'tropicality' and 'development' which together constitute:

"part of one and the same essentialising and generalising cultural discourse: one that denigrates large regions of the world as dangerous - disease-ridden, poverty-stricken and disaster-prone; one that depicts the inhabitants of these regions as inferior untutored, incapable, victims; and that it reposes in western medicine, investment and preventative systems the expertise required to remedy these ills" (p.29)

Whilst the application of the a post-development and post-colonial lens to the concept of 'vulnerability' highlights many continuities in the representation of the 'periphery', Bankoff's article does, however, suffers from a key deficiency. Whilst accurately differentiating between behavioural and structuralist paradigms in the hazard and disaster literature, Bankoff (2002) feels that, in the last instance:

"the two are variants of the same hegemonic discourse that identifies one and the same part of the globe as the abode of mainly disadvantaged people who dwell in poorly governed and environmentally degraded space" (p.28).

In this respect Bankoff (2002) fails to appreciate the manner in which the structuralist paradigm not only highlights the resilience, capacity and capabilities of people exposed to 'natural hazards', but also focuses on the different and location-specific economic, political and social factors which create, maintain and reproduce vulnerability for particular populations. Therefore, I would argue that the structuralist paradigm does not homogenise the 'periphery' to the same extent as the behavioural paradigm. In this respect locating both paradigms as 'variants' of the same undiffentiated 'hegemonic discourse' collapses any differences between structuralist interpretations and representations of disasters and those of environmental determinists in the behavioural paradigm. This is highly unfortunate considering Bankoff's own observation that the behavioural paradigm has a hegemonic position within International Financial Institutions, the UN and many bilateral donors (p.25). 
${ }^{6}$ This terminology departs from economists' usual understanding of risk and uncertainty, as risk is usually seen as having a known probability distribution and uncertainty as having an unknown probability distribution (Devereux 2001).

${ }^{7}$ It is worth highlighting two further distinctions. Firstly, Sinha and Lipton (1999) differentiate between income/production DFs and consumption/well-being DFs with highlight the frequency of 'consumption smoothing' in the face of income/production DFs. Secondly, Sinha and Lipton (1999) distinguish between the different costs die to DFs: Direct costs, opportunity costs, costs of treating and coping, plus overall and direct aversion costs (p.7).

${ }^{8}$ Just as Giddens notes the centrality of risk in the condition of 'becoming modern', Beck (2002) highlights how the idea of controlling risk is inherent to the process of modernisation. In this respect, the shift to 'uncontrollable risk' could be seen to as a reflection of postmodernism with its attendant emphasis on ephemerality and fragmentation (Harvey 1989).

${ }^{9}$ Francis (2002) highlights the point that French concept of society is "one of solidarity around a core of shared values and rights: a conception of society as a moral community" (p.75).

${ }^{10}$ As Fine (2001) indicates, the rise of social capital stems form the work of Bourdieu who highlighted the inter-related roles of social capital, symbolic capital, and cultural capital in processes of social differentiation and the maintenance and use of power. However, Fine argues that social capital has become so divorced from its orig ins, which have been replaced by rational choice theory, that the precise meaning of the term has become so diffuse as to render the term practically meaningless.

${ }^{11}$ One issue which the CPRC does not seem to have engaged with is the increasing importance of HIV/AIDs in creating, maintaining and reproducing chronic poverty, especially in the southern African context. For example see Tibaijuka (1997), Rugalema (2000), and Sibanda (2000).

${ }^{12}$ Sinha and Lipton (1999) also discuss 'natural disasters' through their co-ordinates of 'vulnerability' and 'aversion', as well as through the 'covariance' of disaster risks with other DFs. In their discussion of covariance, Sinha and Lipton assert that "there is some evidence that in areas of high [levels of food] fluctuation fat-storers have been selected over the generations, while muscle-storers dominate areas of low mean and low fluctuation" (p.30). One would expect the authors to have provided specific evidence when making such a contentious assertion.

${ }^{13}$ This definition highlights the importance of socially and culturally constructed notions of risk that are often missing from accounts of risk management which rely purely on information.

${ }^{14}$ Figure 7 shows vulnerability to be a cause of the increase or decrease in the duration of poverty. This is not meant to reduce an understanding of vulnerability to only this dimension, but is due to problems incorporating vulnerability as a symptom, and constituent part, of poverty in the same illustration. 


\section{Bibliography}

Abbott,S. (1991) “Courting Ruin: Disaster Vulnerability" Geographical Magazine, August 1991, pp12-15

Aliber, M (2001) "Study of the incidence and nature of chronic poverty and development policy in South Africa: an overview" CPRC Working Paper 3, Institute for Development

Policy and Management, University of Manchester, (www.chronicpoverty.org) 
Bankoff,G. (2001) "Rendering the World Unsafe: 'Vulnerability' as Western Discourse" Disasters, Vol. 25, No. 1, pp19-35

Baulch, B., and Hoddinott, J. (2000) "Economic mobility and poverty dynamics in developing countries" Journal of Development Studies, Vol. 36, No. 6, pp1-24

Bayliss-Smith,T. (1991) "Food security and agricultural sustainability in the New Guinea Highlands: Vulnerable people, vulnerable places" Institute of Development Studies Bulletin, Vol. 22, No. 3, pp5-11

Beck,U. (2002) "The Terrorist Threat: World Risk Society Revisited" Theory, Culture \& Society, Vol. 19, No. 4, pp39-55

Blaikie,P., Cannon,T., Davis,I. and Wisner,B. (1994) "At Risk: Natural hazards, people's vulnerability and disasters" Routledge : London, UK

Blaike,P. and Brookfield,H.C. (1987) 'Land Degradation and Society" Methuen : London, UK

Bird,K., Hulme,D., Moore,K. and Shepherd,A. (2002) “ Chronic Poverty And Remote Rural Areas" CPRC Working Paper No 13, Institute for Development Policy and Management, University of Manchester, (www.chronicpoverty.org)

Chambers, R. (1983) “Rural Development: Putting the Last First” Longman : Essex, UK

Chambers,R. (1989) "Editorial introduction: Vulnerability, coping and policy" Institute of Development Studies Bulletin, Vol. 20, No. 2, pp1-7

Corbett,J. (1988) 'Famine and Household Coping Strategies" World Development, Vol. 16, No. 9, pp1099-1112

Delor,F. and Hubert,M. (2000) "Revisiting the concept of "vulnerability"” Social Science and Medicine, Vol. 50, pp1557-1570.

Dercon, S. 1999. 'Income Risk, Coping Strategies, and Safety Nets'. Background Paper for the World Development Report 2000/2001. World Bank : Washington D.C http://www.worldbank.org/poverty/wdrpoverty/background/dercon.pdf

Dercon,S. and Krishnan,P. (2000). "Vulnerability, Seasonality, and Poverty in Ethiopia" Journal of Development Studies, Vol.36, No.6, pp25-53

Devereux,S. (2001) "Livelihood Insecurity and Social Protection: A Re-emerging Issue in Rural Development”' Development Policy Review, Vol. 19, No. 4, pp507-519

Devereux,S. (1993) "Goats before ploughs: Dilemmas of household response sequencing during food shortage" Institute of Development Studies Bulletin, Vol. 24, No. 4, pp52-59

Dreze,J. and Sen,A.K. (1989) 'Hunger and Public Action” Clarendon : Oxford, UK

Ellis,F. (2000) "Rural Livelihoods and Diversity in Developing Countries" Oxford University Press : Oxford, UK

Farrington,J., Christoplos,I., Kidd,A. with Beckman,M. (2002) "Extension, Po verty and Vulnerability: The Scope for Policy Reform, Final Report of a Study for the Neuchâtel 
Initiative" Poverty and Agricultural Extension Working Paper 155, Overseas Development Institute, London

Fine,B. (2001) "Social Capital versus Social Theory: Political economy and social science at the turn of the millennium" Routledge : London, UK

Francis,P. (2002) "Social Capital, Civil Society and Social Exclusion" in Kothari,U. and Minogue,M. (ed.) "Development Theory and Practice: Critical Perspectives" Palgrave :

Basingstoke, UK

Harvey, D. (1989) “The Condition of Postmodernity" Blackwell : Oxford, UK

Henninger, N. (1998) 'Mapping and geographic analysis of human welfare and poverty - review and assessment" World Resources Institute : Washington D.C.

http://www.grida.no/prog/global/poverty/pub/pov_fin.pdf

Heslop,A. and Gorman,M. (2002) “ Chronic Poverty and Older People in the Developing World" CPRC Working Paper No 10, Institute for Development Policy and Management, University of Manchester, (www.chronicpoverty.org)

Hewitt,K. (1998) "Excluded perspectives in the social construction of disaster" in Quarantelli,E.L. (1998) 'What is a disaster: Perspectives on the question' Routledge : London, UK

Hulme,D., Moore,K., and Shepherd,A. (2001) "Chronic poverty: meanings and analytical frameworks" CPRC Working Paper 2, Institute for Development Policy and Management, University of Manchester, (www.chronicpoverty.org)

Johnston,R.J., Gregory,D. and Smith,D.M. (1994) “The Dictionary of Human Geography" Blackwell : Oxford, UK

Kaplinski,R. (2000) "Spreading the Gains from Globalisation: what can be learned from value chain analysis?" Working Paper 110, Institute of Development Studies, University of Sussex

Kirkby,J., O'Keefe,P and Howarth,C. (2001) “Introduction: Rethinking Environment and Development in Africa and Asia" Land Degradation and Development, Vol. 12, pp195203

Kothari,U. (2002) “Migration And Chronic Poverty" CPRC Working Paper 16, Institute for Development Policy and Management, University of Manchester, (www.chronicpoverty.org)

Kothari,U. and Minogue,M. (ed.) (2002) "Development Theory and Practice: Critical Perspectives" Palgrave : Basingstoke, UK

Kozel, V. and Parker, B. (2001) "Poverty in Rural India: The Contribution of Qualitative Research in Poverty" World Bank

Lok-Dessallien,R. (1998) “Review of Poverty Concepts and Indicators" Poverty

Elimination Programme, UNDP http://www.undp.org/poverty/publications/pov_red/

Marcus,R. and Wilkinson,J. (2002) “Whose Poverty Matters? Vulnerability, Social

Protection and PRSPs" Childhood Poverty Research and Policy Centre Working Paper No 
1, Institute of Development Policy and Management, University of Manchester, (www.chronicpoverty.org)

Mehta,A.K. and Shah,A. (2001) “Chronic Poverty in India: Overview Study” CPRC Working Paper 7, Institute for Development Policy and Management, University of Manchester, (www.chronicpoverty.org)

Moore, K. 2001. "Frameworks for understanding the intergenerational transmission of poverty and well-being in developing countries" CPRC Working Paper 8 , Institute for Development Policy and Management, University of Manchester, (www.chronicpoverty.org)

Morduch,J. (1994) "Poverty and Vulnerability" The American Economic Review, Vol. 84, No. 2, pp221-225

Moser,C. (1998) “The Asset Vulnerability Framework: Reassessing Urban Poverty Reduction Strategies" World Development Vol. 26, No. 1, pp1-19

Murray,C. (2001) 'Livelihoods research: some conceptual and methodological issues" CPRC Working Paper No 5, Institute for Development Policy and Management, University of Manchester, (www.chronicpoverty.org)

Oliver-Smith, A. (1996) "Anthropological Research on Hazards and Disasters" Annual Review of Anthropology", Vol. 25 pp303-328

Okidi,J.A. and Mugambe,G.K. (2002) "An Overview of Chronic Poverty and Development Policy in Uganda" CPRC Working Paper 11, Institute for Development Policy and Management, University of Manchester, (www.chronicpoverty.org)

Quarantelli,E.L. (1998) 'What is a disaster: Perspectives on the question' Routledge : London, UK

Rugalema,G. (2000) "Coping or Struggling? A journey into the impact of HIV/AIDS in Southern Africa", Review of African Political Economy, No. 86, pp537-545.

Sen,A. (1981) "Poverty and famines: An essay on entitlement and deprivation" Clarendon Press : Oxford

Sen,A. (1984) “Resources, Values and Development” Blackwell : Oxford

Sen,A. (1999) “Development as Freedom” Oxford University Press : Oxford, UK

Sibanda,A. (2000) "A Nation in Pain: Why the HIV/AIDS epidemic is out of control in Zimbabwe", International Journal of Health Services, Vol. 30, No. 4, pp717-738

Sinha,S. and Lipton,M. (1999) "Damaging Fluctuations, Risk and Poverty: A Review" Background Paper for the World Development Report 2000/2001, Poverty Research Unit, University of Sussex

Smith,K. 1996 'Environmental Hazards: Assessing Risk and Reducing Disaster” London : Routledge 
Tibaijuka,A.K. (1997) "AIDS and economic welfare in peasant agriculture: Case studies from Kagabiro village, Kagera region, Tanzania”, World Development, Vol. 25, No. 6, pp963975.

Tudawe,I. (2002) "Chronic Poverty and Development Policy in Sri Lanka: Overview Study" CPRC Working Paper No 9, Institute for Development Policy and Management, University of Manchester, (www.chronicpoverty.org)

Watts,M.J. and Bohle,H.G. (1993) "The Space of Vulnerability: the causal structure of hunger and famine", Progress in Human Geography, Vol. 17, No. 1, pp43-67.

Webb,P. and Harinarayan,A. (1999) "A measure of uncertainty: The nature of vulnerability and its relationship to malnutrition" Disasters, Vol.23, No.4, pp292-305.

Wisner,B. (1993) "Disaster Vulnerability: Scale, Power and Daily Life", GeoJournal, Vol. 30, No. 2, pp127-140

Wood,G. (2000) “Concepts and Themes: Landscaping Social Development" SD SCOPE Paper No. 9 : Centre for Development Studies, University of Bath

Yaqub, S. (2000) “Intertemporal Welfare Dynamics: Extents and Causes" Conference paper given at Brookings Institution/Carnegie Endowment Workshop, 'Globalization: New Opportunities, New Vulnerabilities' http://www.ceip.org/files/pdf /shahin_dynamics.pdf 